\title{
Communication
}

\section{Room Temperature Operation of UV Photocatalytic Functionalized AlGaN/GaN Heterostructure Hydrogen Sensor}

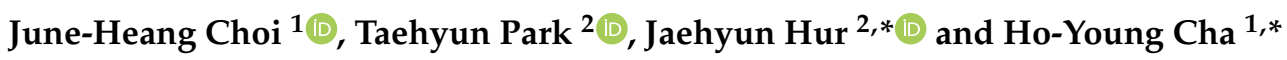 \\ 1 School of Electronic and Electrical Engineering, Hongik University, Seoul 04066, Korea; \\ petrus0314@mail.hongik.ac.kr \\ 2 Department of Chemical and Biological Engineering, Gachon University, Seongnam 13120, Gyeonggi, Korea; \\ thpark@gachon.ac.kr \\ * Correspondence: jhhur@gachon.ac.kr (J.H.); hcha@hongik.ac.kr (H.-Y.C.)
}

check for updates

Citation: Choi, J.-H.; Park, T.; Hur, J.; Cha, H.-Y. Room Temperature Operation of UV Photocatalytic Functionalized AlGaN/GaN Heterostructure Hydrogen Sensor. Nanomaterials 2021, 11, 1422. https:// doi.org/10.3390/nano11061422

Academic Editor: Gabriella Caminati

Received: 13 April 2021

Accepted: 25 May 2021

Published: 28 May 2021

Publisher's Note: MDPI stays neutral with regard to jurisdictional claims in published maps and institutional affiliations.

\begin{abstract}
An AlGaN/GaN heterostructure based hydrogen sensor was fabricated using a dual catalyst layer with ZnO-nanoparticles (NPs) atop of Pd catalyst film. The ZnO-NPs were synthesized to have an average diameter of $\sim 10 \mathrm{~nm}$ and spin coated on the Pd catalyst layer. Unlike the conventional catalytic reaction, the fabricated sensors exhibited room temperature operation without heating owing to the photocatalytic reaction of the ZnO-NPs with ultraviolet illumination at $280 \mathrm{~nm}$. A sensing response of $25 \%$ was achieved for a hydrogen concentration of $4 \%$ at room temperature with fast response and recovery times; a response time of $8 \mathrm{~s}$ and a recovery time of $11 \mathrm{~s}$.
\end{abstract}

Keywords: AlGaN/GaN; ZnO-nanoparticles; Pd; photocatalyst; hydrogen sensor; ultraviolet

\section{Introduction}

Hydrogen is presently being studied as an alternative energy source for eco-friendly renewable energy generation instead of fossil fuels [1,2]. The successful utilization of hydrogen requires highly sensitive and reliable safety sensors. For example, hydrogen explosions occur at concentrations exceeding 4.65\% [3-5]; therefore, the sensor must detect low levels of hydrogen quickly and accurately.

Among various types of sensors, an FET-type sensor with a catalytic gate material has been widely studied due to its compact size and low power consumption. A catalytic reaction with a target gas changes the surface potential of FET, which in turn modulates the FET current [5-7].

Gallium nitride $(\mathrm{GaN})$ has a wide energy bandgap of $3.4 \mathrm{eV}$ [8-13], which results in a low intrinsic carrier density allowing $\mathrm{GaN}$ to maintain its semiconductor properties at much temperatures higher than those possible with Si or GaAs. When an AlGaN/GaN heterostructure is formed, a 2-dimensional electron gas (2DEG) channel is created with high mobility at the interface [14-16]. Since the AlGaN thickness is generally of the order of a few tens of nanometers, the channel current strongly depends on the surface potential change, thus resulting in sensitive responses from the sensor. Therefore, an AlGaN/GaN heterostructure would be a great candidate for the sensing platform.

Various catalysts have been investigated for use in hydrogen sensors, including metals and metal oxides. $\mathrm{Pt}, \mathrm{Pd}$, and $\mathrm{Ru}$ are known to have high hydrogen solubility [17-26]. Metal oxides, such as $\mathrm{ZnO}, \mathrm{TiO}_{2}, \mathrm{SnO}_{2}, \mathrm{WO}_{2}, \mathrm{PdO}, \mathrm{In}_{2} \mathrm{O}_{3}$, and $\mathrm{Fe}_{2} \mathrm{O}_{3}$, have been studied mostly as resistive sensors where adsorbed oxygen ions play an important role in the reaction mechanism [27-40].

Since the typical catalytic reaction with hydrogen occurs at elevated temperatures [41], the sensor module must be heated using a separate or integrated heater, which incurs extra power and time for stabilization. In addition, thermal heating of the catalyst and sensor platform degrades long-term reliability [42]. Therefore, there is a strong demand for a hydrogen sensor operating at room temperature without heating. A possible solution would 
be a photocatalytic reaction where the gas reaction with catalyst material is accelerated by photoreaction. Indeed, it was reported that metal oxides reacted with hydrogen at room temperature with exposure to ultraviolet (UV) light [43-47]. In this study, an AlGaN/GaN FET sensor was fabricated using a dual catalyst layer with ZnO-nanoparticles (NPs) atop of Pd catalyst film, which exhibited room temperature sensing capability of hydrogen with UV illumination.

\section{Experiment and Results}

Figure 1 illustrates the synthesis process of $\mathrm{ZnO}-\mathrm{NPs}$. The precursor solution was the hydrolysis of $\mathrm{Zn}\left(\mathrm{CH}_{3} \mathrm{COO}\right)_{2} \cdot 2 \mathrm{H}_{2} \mathrm{O}$ (Sigma-Aldrich, St. Louis, MO, USA) with $\mathrm{KOH}$ (Samchun, Samchun, Seoul, South Korea, 95\%) in methanol (Sigma-Aldrich, St. Louis, MO, USA, 99.9\%). ZnO-NPs formed after $2 \mathrm{~h}$ reaction were separated by centrifugation. A detailed synthesis process and the characterization for the synthesized ZnO-NPs can be found in ref [48].

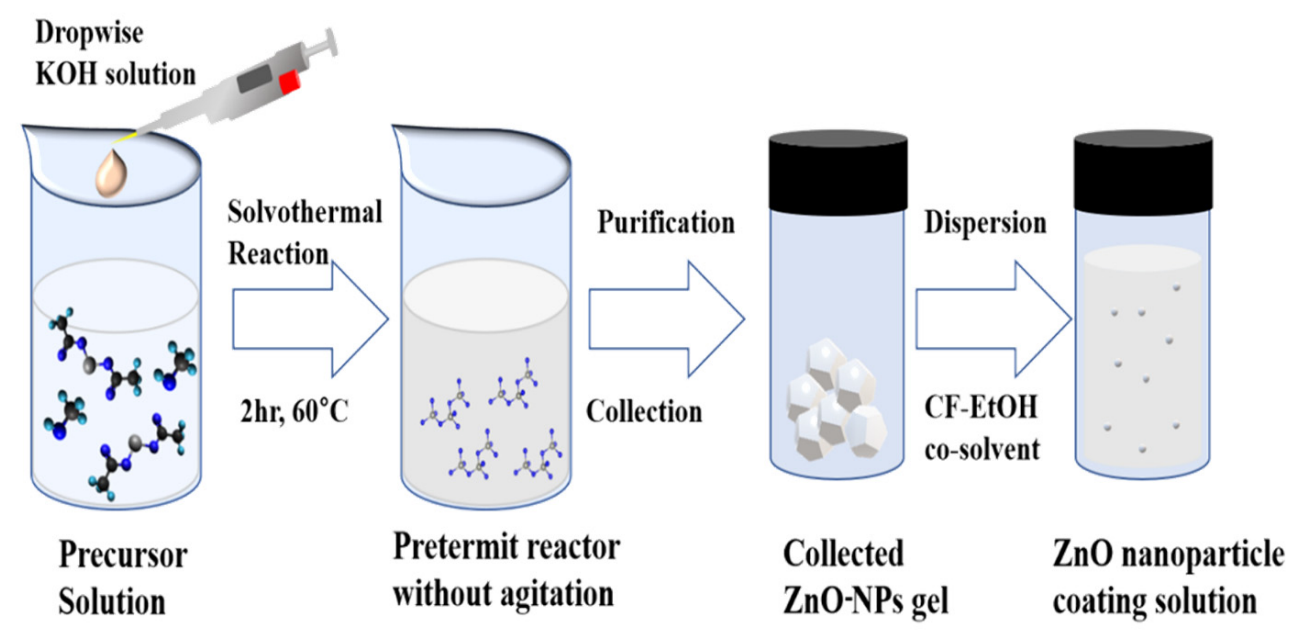

Figure 1. Synthesis process for $\mathrm{ZnO}-\mathrm{NPs}$.

The crystal structure of the ZnO-NPs was investigated using powder X-ray diffraction, which is shown in Figure 2a. The crystal planes of the crystalline ZnO-NPs corresponding to the observed diffraction peaks are indicated in the plot, confirming the successful synthesis of ZnO-NPs. The internal and surface chemical bonding state of ZnO-NPs was analyzed through $\mathrm{X}$-ray photoelectron spectroscopy (XPS). Figure $2 \mathrm{~b}$ represents the $\mathrm{O}$ 1 s spectrum of $\mathrm{ZnO}-\mathrm{NPs}$ where three distinct binding energy peaks were observed at $529.6,531.0$, and $532.1 \mathrm{eV}$, which corresponded to the $\mathrm{O}$ atom in the $\mathrm{Zn}-\mathrm{O}$ bonding (lattice oxygen), oxygen sublattice imperfection (oxygen vacancy) and surface adsorbed $\mathrm{O}_{2}{ }^{-}$of ZnO-NPs, respectively [49-51]. This XPS result demonstrates the presence of the ionized oxygen molecules at the $\mathrm{ZnO}-\mathrm{NP}$ surface, which plays an important role in the catalytic reaction under UV illumination. The absorption spectrum of ZnO-NPs as a function of wavelength was also measured to estimate the optical bandgap of ZnO-NPs. Figure 3a,b show the absorption spectrum and Tauc plot of the ZnO-NPs thin film from which the optical bandgap was estimated to be $3.24 \mathrm{eV}$. The wide band gap of ZnO-NPs can selectively absorb UV light that can remove the oxygen molecules adsorbed on the ZnO-NPs surface. 

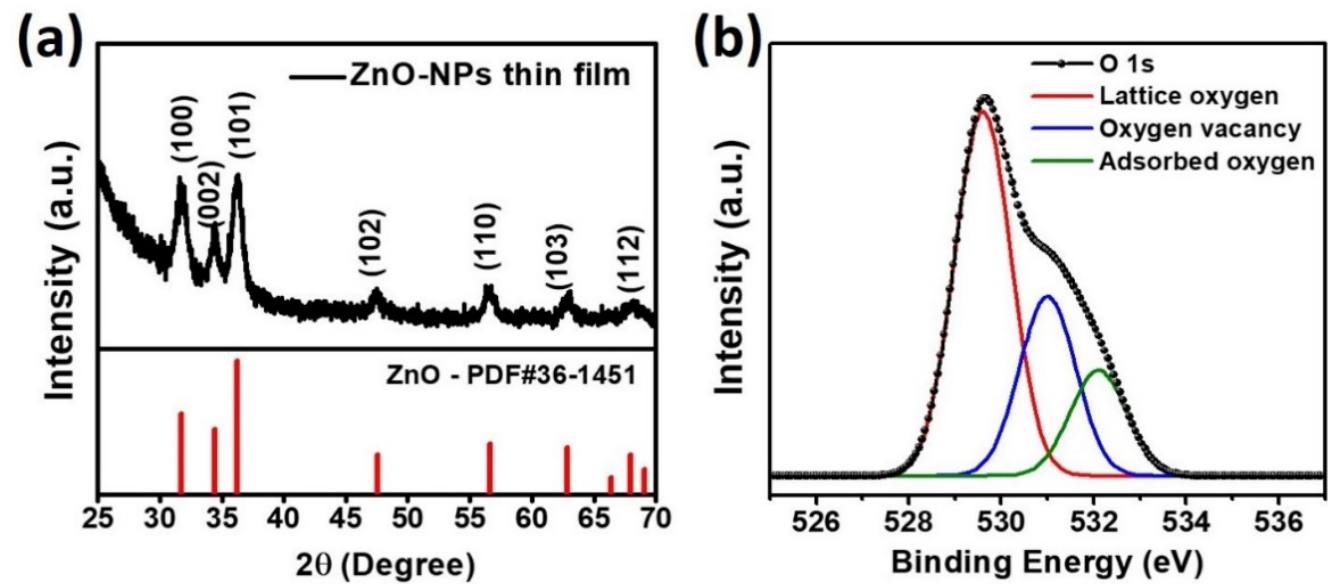

Figure 2. (a) X-ray diffraction pattern and (b) O 1s XPS spectra of as-synthesized ZnO-NPs.
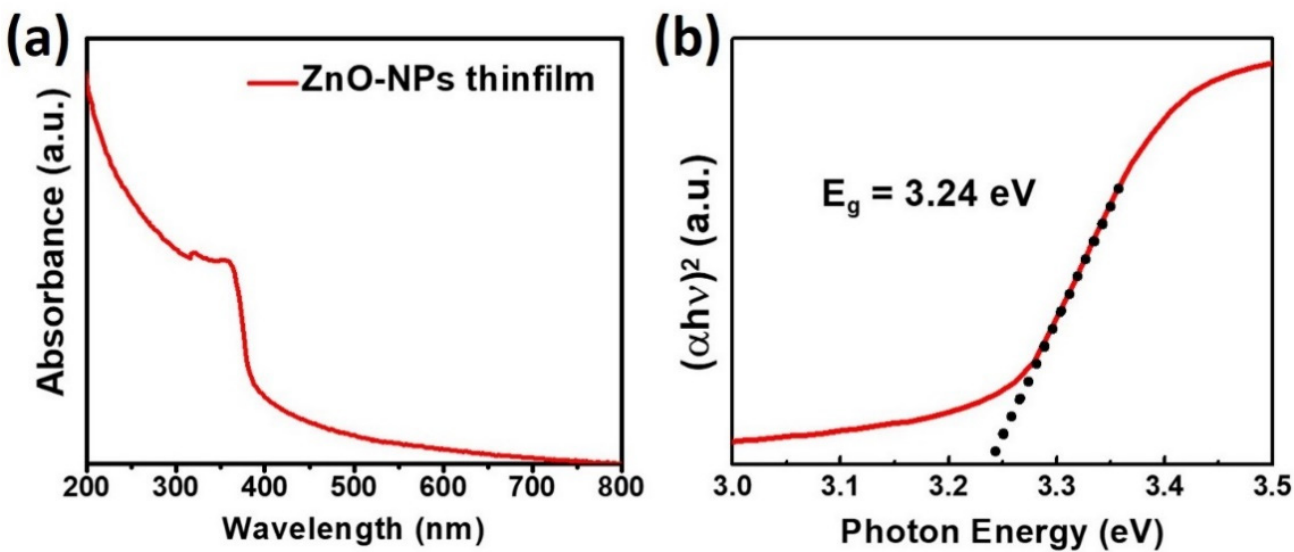

Figure 3. (a) Absorption spectrum and (b) Tauc plot of $\mathrm{ZnO}-\mathrm{NPs}$ thin film.

Figure 4a,b shows Transmission Electron Microscopy (TEM) and High-Resolution TEM (HRTEM) images of ZnO-NPs, respectively. The size of ZnO-NPs was in the range of $5-10 \mathrm{~nm}$. The lattice fringe spacings of 0.28 and $0.25 \mathrm{~nm}$ observed in HRTEM image are related to (100) and (101) planes of the ZnO-NPs, respectively. Other crystalline planes such as (102) and (110) were also confirmed from the Fast Fourier transform (FFT) pattern shown in the inset of Figure $4 \mathrm{~b}$.

(a)

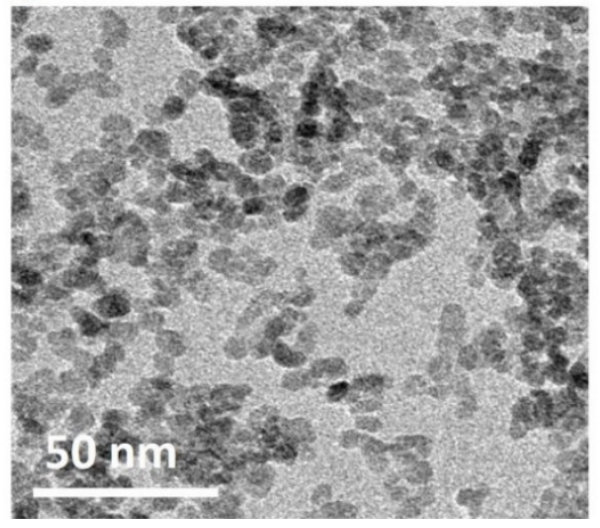

(b)

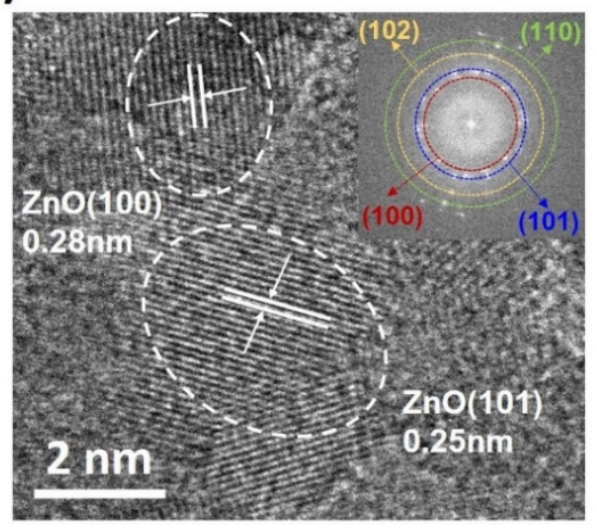

Figure 4. (a) TEM and (b) HRTEM image of as-synthesized ZnO NPs (inset: FFT pattern). 
The AlGaN/GaN epitaxial structure used for sensor fabrication comprised a $10 \mathrm{~nm}$ in situ $\mathrm{SiN}_{\mathrm{x}}$ passivation layer, a $3.5 \mathrm{~nm} \mathrm{GaN}$ layer, a $23 \mathrm{~nm} \mathrm{Al}_{0.24} \mathrm{Ga}_{0.76} \mathrm{~N}$ layer, and a $4.2 \mu \mathrm{m}$ GaN layer on a Si (111) substrate. After defining the ohmic contact region, the exposed in-situ $\mathrm{SiN}_{\mathrm{x}}$ layer was etched using $\mathrm{SF}_{6}$-based inductively coupled plasma reactive ion etching (ICP-RIE) and the underlying GaN and AlGaN layers were etched down to the middle of the AlGaN layer using $\mathrm{Cl}_{2} / \mathrm{BCl}_{2}$-based ICP-RIE. A Ti/Al/Ni/Au metal stack was evaporated as the ohmic contact metal and a rapid thermal annealing process was carried out at $830{ }^{\circ} \mathrm{C}$ for $30 \mathrm{~s}$ in an $\mathrm{N}_{2}$ ambient. Then, device isolation was performed using the same etching process used for the ohmic contact formation, with a larger etch depth of $350 \mathrm{~nm}$. The pad electrodes were formed using a Ti/Au metal stack. Then, the catalyst area was defined by photolithography. In order to lower the standby current to achieve high sensitivity [52], the catalyst area was also recessed using the same plasma etching method used for the ohmic contact process. The final thickness of the AlGaN layer after being etched was $10 \mathrm{~nm}$. After evaporating a $30 \mathrm{~nm}$ Pd catalyst layer, the sensor surface was passivated with a $100 \mathrm{~nm} \mathrm{SiN}_{\mathrm{x}}$ film. The passivation film on the catalyst region and pad contact area were etched using a $\mathrm{SF}_{6}$-based ICP-RIE. The synthesized ZnO-NPs were spin coated on the Pd layer after being dispersed in chloroform/ethanol solution using an ultrasonicator for $2 \mathrm{~h}$. Finally, the sample was annealed at $120^{\circ} \mathrm{C}$ for $1 \mathrm{~h}$. The thicknesses of the $\mathrm{ZnO}-\mathrm{NP}$ layer was $170 \mathrm{~nm}$. The fabricated sensor with the $\mathrm{ZnO}-\mathrm{NP} / \mathrm{Pd}$ dual catalyst layer is illustrated in Figure 5, where the inset is the cross-sectional TEM image of the dual catalyst layer.

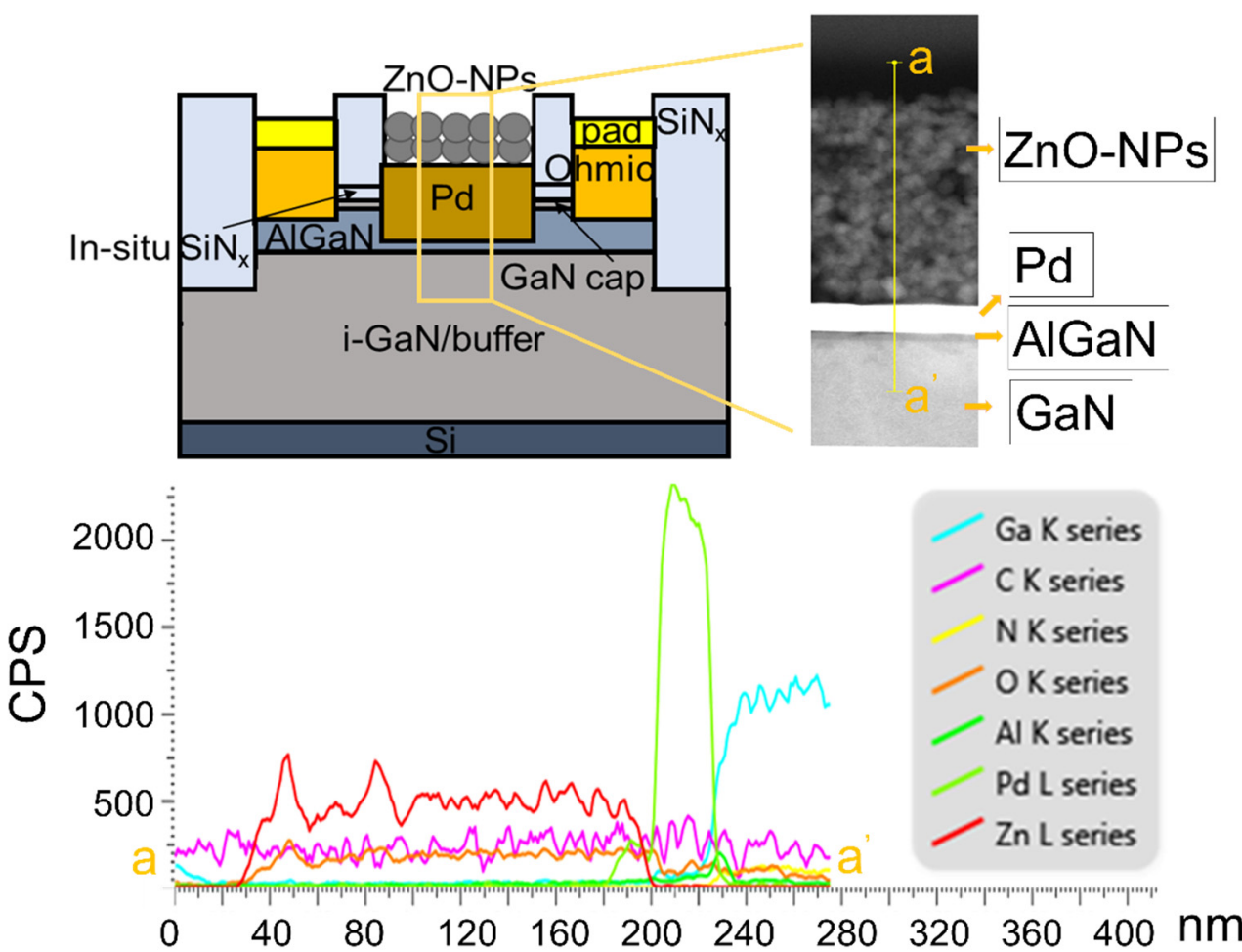

Figure 5. Cross-sectional schematic of $\mathrm{AlGaN} / \mathrm{GaN}$ based hydrogen sensor with a dual catalyst layer. The inset shows the cross-sectional TEM image of the dual catalyst layer of $\mathrm{ZnO}-\mathrm{NP} / \mathrm{Pd}$.

Sensor characteristics were measured at room temperature with and without UV illumination, where the UV light source was a $280 \mathrm{~nm}$ LED operated by a driving current of $180 \mathrm{~mA}$ resulting in an optical power density of $1.82 \mathrm{~W} / \mathrm{cm}^{2}$ at the catalyst surface. The hydrogen concentration used for the tests was $4 \%$.

The current-voltage characteristics without and with UV illumination at $280 \mathrm{~nm}$ are compared in Figure 6a,b, respectively. While little changes were observed in the sensor current under hydrogen injection without UV illumination, a significant increase was 
observed under hydrogen injection with UV illumination. The sensing mechanism is illustrated in Figure 7. There are negatively ionized oxygen species $\left(\mathrm{O}_{2}{ }^{-}(\mathrm{ad})\right)$ adsorbed at the $\mathrm{ZnO}$ surface in air, which have strong adhesive energy at room temperature, making it difficult to react with hydrogen [44]. Therefore, the hydrogen sensing response at room temperature is very low. With UV illumination, electron-hole pairs are generated in $\mathrm{ZnO}$, and holes react with $\mathrm{O}_{2}{ }^{-}$(ad) to produce oxygen gas molecules. Additionally, the gas molecules are ionized again by reacting with photogenerated electrons $\left(\mathrm{O}_{2}{ }^{-}(\mathrm{h} v)\right)$. These photoinduced ionized oxygen species have weak adhesive energy enabling hydrogen reaction at room temperature [53]. Removing oxygen ion species from the surface acts as a positive surface potential of the $\mathrm{AlGaN} / \mathrm{GaN}$ FET sensor, which increases the sensor current. Therefore, hydrogen sensing is possible at room temperature with UV illumination. This effect is boosted in $\mathrm{ZnO}-\mathrm{NPs}$ because of their large surface-to-volume ratios resulted from the small size of $\mathrm{ZnO}-\mathrm{NPs}$. The increased standby current with UV illumination is due to the removed $\mathrm{O}_{2}{ }^{-}(\mathrm{ad})$ from the surface.

The sensing response characteristics are defined by [54]:

$$
\text { Response }[\%]=\left(\frac{I_{g a s}-I_{a i r}}{I_{\text {air }}}\right) \times 100,
$$

where $I_{g a s}$ is the sensor current with $4 \%$ hydrogen injection, and $I_{a i r}$ is the sensor current without hydrogen injection. The extracted sensing response characteristics without and with UV illumination are shown in Figure $6 c, d$, respectively. Remarkable enhancement in the sensing response was observed with UV illumination. A response of $\sim 25 \%$ was observed at a bias voltage of $5 \mathrm{~V}$.
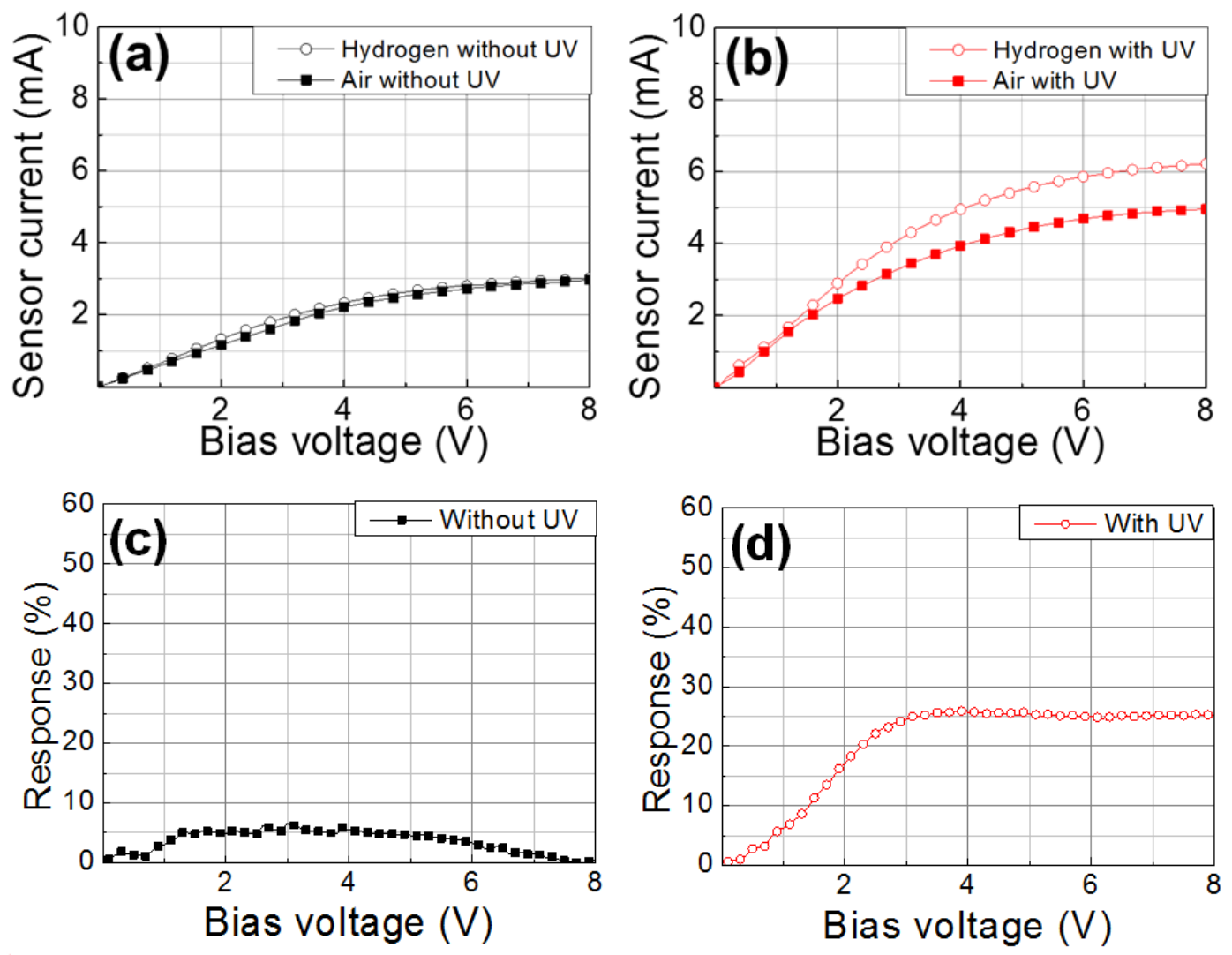

Figure 6. Sensing characteristics of a fabricated AlGaN/GaN based hydrogen sensor with ZnO-NP/Pd dual catalyst layer at room temperature without and with UV illumination; current-voltage characteristics (a) without and (b) with UV illumination and the corresponding response characteristics (c) without and (d) with UV illumination. 

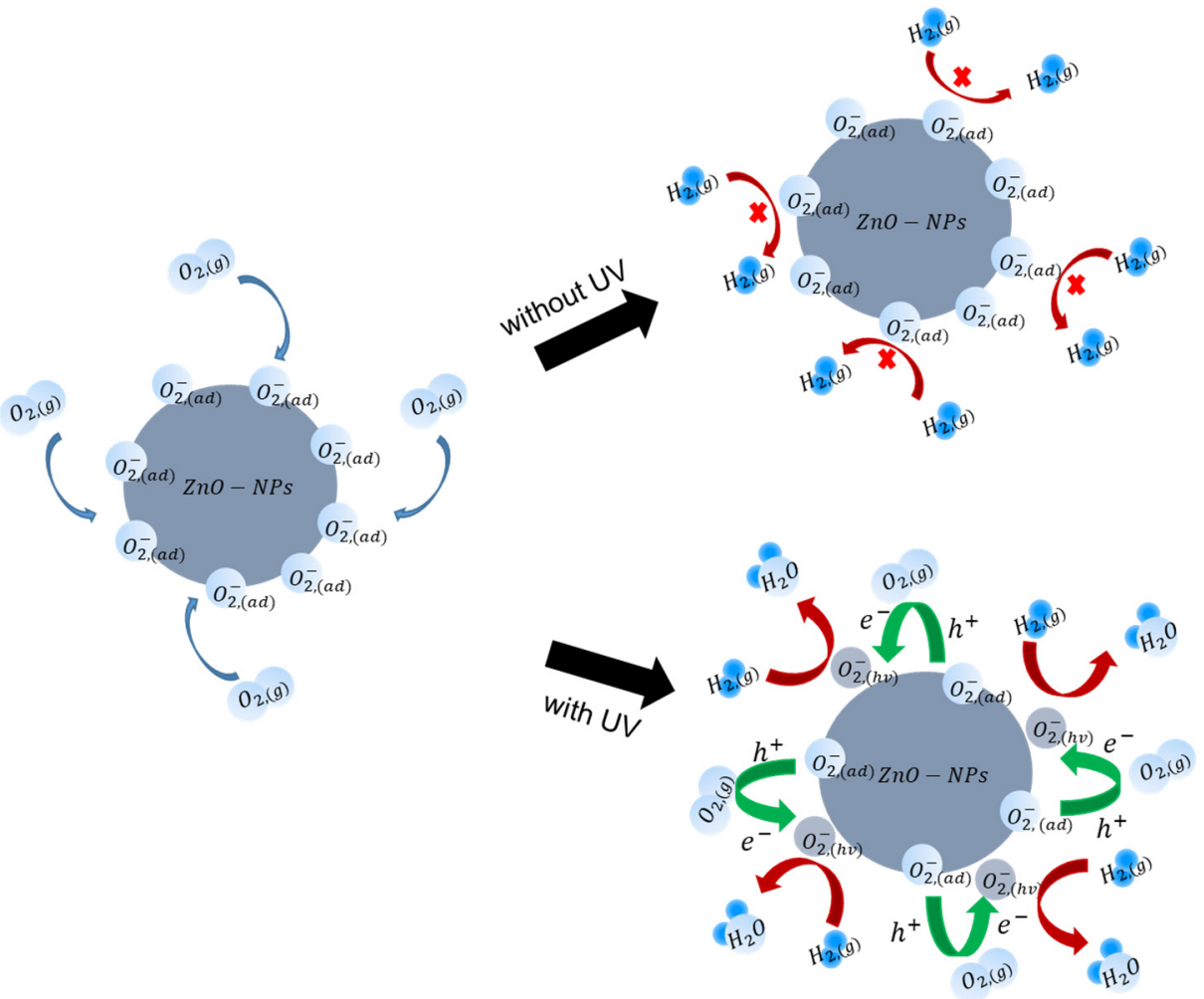

Figure 7. Schematic illustration of UV photocatalytic reaction of hydrogen with ZnO-NP.

The sensing repeatability and time transient characteristics were examined at room temperature using a bias voltage of $5 \mathrm{~V}$. Hydrogen gas with $4 \%$ concentration was injected for $20 \mathrm{~s}$ and paused for the subsequent $40 \mathrm{~s}$, and this process was repeated. As shown in Figure $8 a$, stable operations with good repeatability characteristics are observed for both the cases with and without UV illumination. The magnified time transient characteristics are shown in Figure 8b, where the response and recovery times with UV illumination are $8 \mathrm{~s}$ and $11 \mathrm{~s}$, respectively, whereas those without UV illumination are $12 \mathrm{~s}$ and $18 \mathrm{~s}$, respectively. The response and recovery times were defined as the durations required for the response current to reach $90 \%$ and $10 \%$ of the saturation current, respectively.
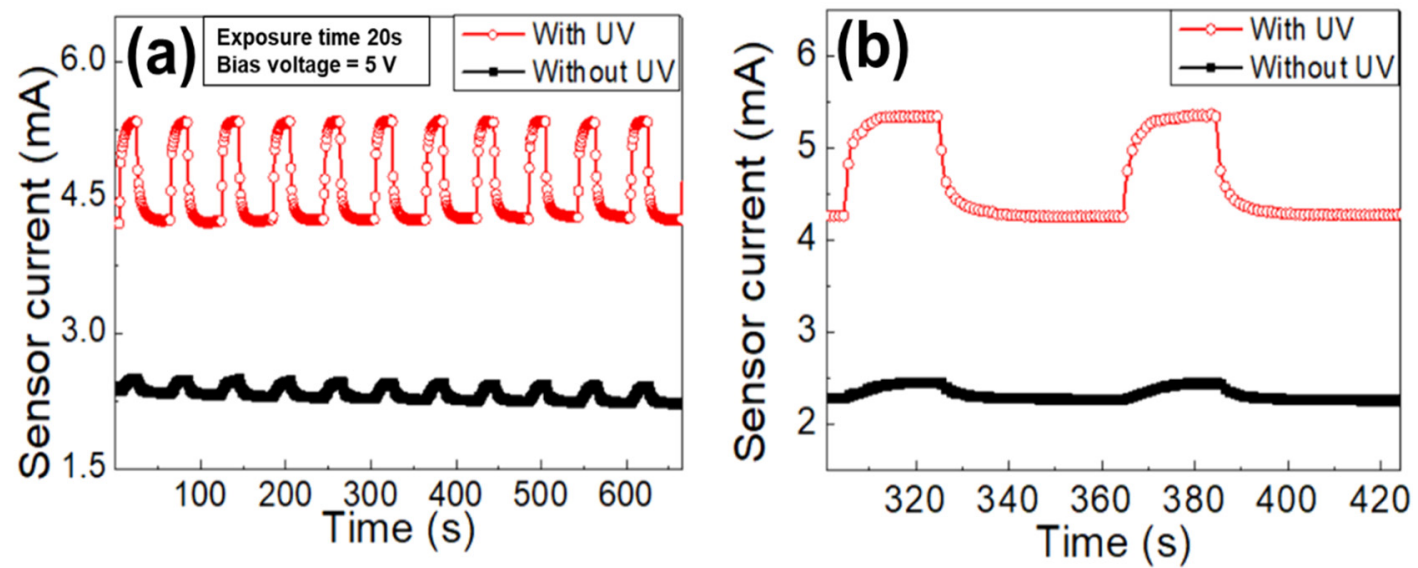

Figure 8. (a) Sensing repeatability characteristics of AlGaN/GaN hydrogen sensor with and without UV illumination and (b) zoom-in time transient characteristics.

The hydrogen concentration dependent response characteristics were also investigated at room temperature with UV illumination during which the hydrogen concentration was 
varied from $0.1 \%$ to $4 \%$. The hydrogen gas was injected for $20 \mathrm{~s}$ at each concentration and the sensor was biased at 5 V. As shown in Figure 9, the sensing current exhibited strong dependency on hydrogen concentration over the entire range; the current increases with increasing hydrogen concentration.

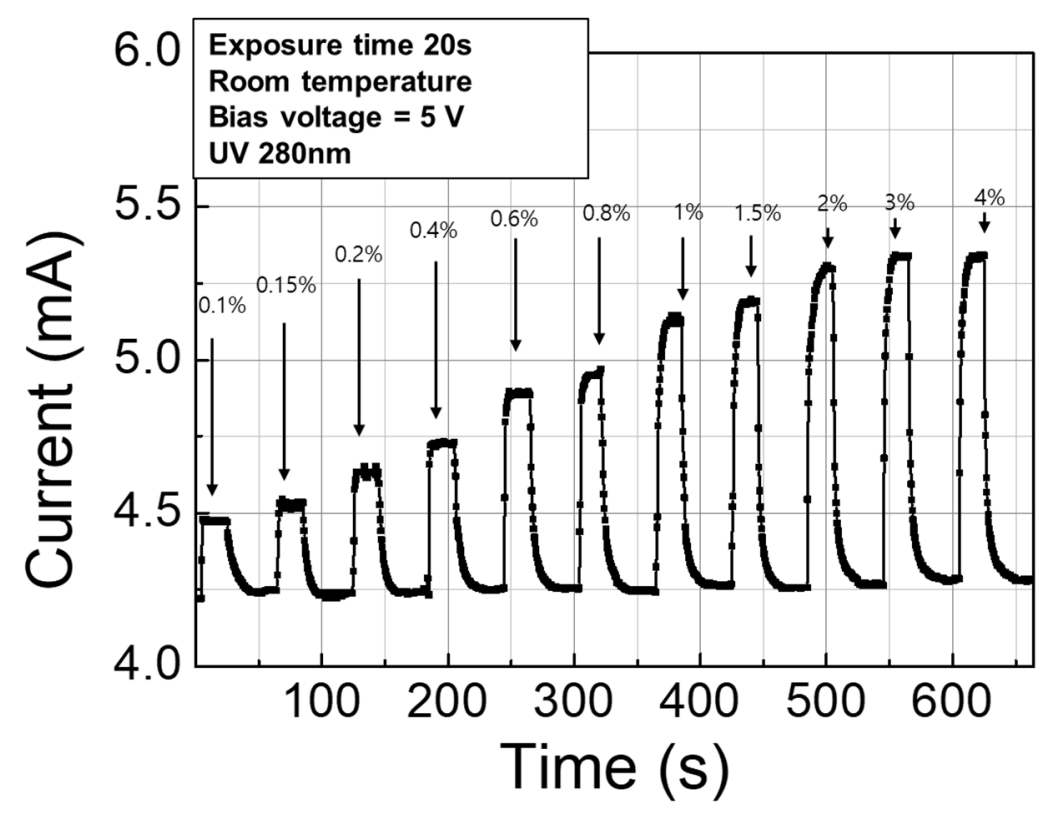

Figure 9. Hydrogen concentration dependent response characteristics of AlGaN/GaN hydrogen sensor at room temperature with UV illumination.

In Table 1, the sensor characteristics are compared with other hydrogen sensors reported at room temperature. The hydrogen sensor fabricated in this work exhibited very fast response and recovery characteristics with a wide detection range. It is suggested that the sensing response can be further improved by employing a thinner $\mathrm{AlGaN}$ barrier layer that can reduce the standby current $\left(I_{\text {air }}\right.$ in Equation (1)) level [55].

Table 1. Comparison of hydrogen sensor characteristics reported at room temperature.

\begin{tabular}{|c|c|c|c|c|c|c|c|}
\hline Sensor Type & Catalyst & Catalyst Structure & $\begin{array}{c}\text { Hydrogen } \\
\text { Concentration }\end{array}$ & $\begin{array}{c}\text { Response } \\
\text { Time }\end{array}$ & $\begin{array}{l}\text { Recovery } \\
\text { Time }\end{array}$ & $\begin{array}{c}\text { Sensor } \\
\text { Response }\end{array}$ & Ref \\
\hline Resistive & $\mathrm{Au} / \mathrm{ZnO}$ & Nanoparticle & $0.0005 \%$ & $4 \mathrm{~s}$ & $24 \mathrm{~s}$ & $21.5 \%$ & [44] \\
\hline Resistive & $\mathrm{ZnO}$ & Nanoline & $0.01 \%$ & $\sim 12 \mathrm{~min}$ & $\sim 20 \mathrm{~min}$ & $19 \%$ & [53] \\
\hline Resistive & $\mathrm{Pd}$ & Nanowire & $0.15 \%$ & $\sim 10 \mathrm{~min}$ & $\sim 10 \mathrm{~min}$ & $9.1 \%$ & [56] \\
\hline Resistive & $\mathrm{Pt}$ & Nanoparticle/nanowire & $0.2 \%$ & - & - & $62 \%$ & [57] \\
\hline Resistive & Pd & Nanoparticle/nanofiber & $0.1 \%$ & $\sim 6 \mathrm{~s}$ & $\sim 3 \mathrm{~s}$ & $12.09 \%$ & [58] \\
\hline Resistive & $\mathrm{Pt} / \mathrm{SnO}_{2}$ & Nanoparticle/nanoparticle & $0.1 \%$ & $\sim 20 \mathrm{~s}$ & $\sim 80 \mathrm{~s}$ & $10,500 \%$ & [59] \\
\hline Resistive & $\mathrm{ZnO}$ & Nanorod & $0.05 \%$ & $\sim 15 \mathrm{~min}$ & $\sim 20 \mathrm{~s}$ & $4.2 \%$ & [60] \\
\hline Resistive & $\mathrm{W}_{18} \mathrm{O}_{4}$ & Nanowire & $0.0002 \%$ & - & - & $\sim 1 \%$ & [61] \\
\hline Resistive & $\mathrm{VO}_{2}$ & Nanobelts & $0.014 \%$ & $\sim 840 \mathrm{~s}$ & $\sim 455 \mathrm{~s}$ & $\sim 1800 \%$ & [62] \\
\hline Resistive & $\mathrm{SnO}_{2}$ & Nanoparticle & $0.1 \%$ & $205 \mathrm{~s}$ & $116 \mathrm{~s}$ & $600 \%$ & [63] \\
\hline Resistive & $\mathrm{SnO}_{2}$ & Nanobelts & $2 \%$ & $\sim 220 \mathrm{~s}$ & $\sim 220 \mathrm{~s}$ & $50 \%$ & [64] \\
\hline Resistive & $\mathrm{Pd}$ & Nanoparticle/nanotube & $1 \%$ & $2 \mathrm{~min}$ & $1.5 \mathrm{~min}$ & $9.5 \%$ & [65] \\
\hline $\begin{array}{c}\text { Diode } \\
\text { (AlGaAs MOS) }\end{array}$ & $\mathrm{Pd}$ & Thin film & $1 \%$ & $58 \mathrm{~s}$ & - & $155.9 \%$ & {$[66]$} \\
\hline $\begin{array}{c}\text { Diode } \\
\text { (AlGaAs } \\
\text { Schottky) }\end{array}$ & $\mathrm{Pd}$ & Thin film & $1 \%$ & $400 \mathrm{~s}$ & - & $\sim 5 \%$ & \\
\hline $\begin{array}{c}\text { Diode } \\
\text { (GaN Schottky) }\end{array}$ & $\mathrm{Pt}$ & Thin film & $1 \%$ & $15 \mathrm{~s}$ & $19 \mathrm{~s}$ & $1 \times 10^{5 \%}$ & [67] \\
\hline $\begin{array}{c}\text { FET } \\
(\mathrm{AlGaN} / \mathrm{GaN})\end{array}$ & $\mathrm{ZnO} / \mathrm{Pd}$ & Nanoparticle/thin film & $4 \%$ & $8 \mathrm{~s}$ & $11 \mathrm{~s}$ & $25 \%$ & $\begin{array}{l}\text { This } \\
\text { work }\end{array}$ \\
\hline
\end{tabular}




\section{Conclusions}

UV-assisted photocatalytic hydrogen sensing capability was demonstrated at room temperature using an $\mathrm{AlGaN} / \mathrm{GaN}$ based sensor with a dual catalyst layer of $\mathrm{ZnO}-\mathrm{NP} / \mathrm{Pd}$. A sensing response of $25 \%$ with a response time of $8 \mathrm{~s}$ and a recovery time of $11 \mathrm{~s}$ was achieved for a hydrogen concentration of $4 \%$ at room temperature under $280 \mathrm{~nm}$ UV illumination. The room temperature operation can thus eliminate the process of heating that is generally required for hydrogen catalytic reactions using conventional materials. Therefore, the proposed sensor has advantages of less power consumption and no need for stabilization. To the best of our knowledge, this is the first demonstration of the operation of a UV-assisted AlGaN/GaN hydrogen sensor at room temperature.

Author Contributions: Conceptualization, experiments, data curation, writing—original draft, J.H.C.; experiments, data curation, T.P.; investigation, writing - review and editing, J.H.; funding acquisition, investigation, supervision, writing - review and editing, H.-Y.C. All authors have read and agreed to the published version of the manuscript.

Funding: This work was supported by the Korea Institute for Advancement of Technology (KIAT) grant funded by the Korean Government (MOTIE) (P07820002101, The Competency Development Program for Industry Specialist) and Basic Science Research Programs (2015R1A6A1A03031833 and 2019R1A2C1008894) through the National Research Foundation of Korea (NRF).

Acknowledgments: Authors would like to thank Wontae Choi for his assistance in sensor measurements.

Conflicts of Interest: The authors declare no conflict of interest.

\section{References}

1. Das, D. Advances in biohydrogen production process: An approach towards commercialization. Int. J. Hydrogen Energy 2009, 34, 7349-7357. [CrossRef]

2. Jeon, J.; Kim, S.J. Recent Progress in Hydrogen Flammability Prediction for the Safe Energy System. Energies 2020, 13, 6263. [CrossRef]

3. Wang, X.; La, C.K. An analysis of the explosion limit of hydrogen oxygen mixtures. J. Chem. Phys. 2013, 138, 134305.

4. Steinberg, M.; Cheng, H.C. Modern and prospective technologies for hydrogen production from fossil fuels. Int. J. Hydrogen Energy 1989, 14, 797-820. [CrossRef]

5. Sharman, B.; Kim, J.S. MEMS based highly sensitive dual FET gas sensor using graphene decorated Pd-Ag alloy nanoparticles for $\mathrm{H}_{2}$ detection. Sci. Rep. 2018, 8, 5902. [CrossRef] [PubMed]

6. Shin, W.J.; Hong, S.B.; Jung, G.W.; Jeong, Y.J.; Park, J.W.; Kim, D.H.; Jang, D.K.; Park, B.G.; Lee, J.H. Improved signal-to-noise-ratio of FET-type gas sensors using body bias control and embedded micro-heater. Sens. Actuators B Chem. 2021, 329, 129166. [CrossRef]

7. Hong, S.B.; Wu, M.; Hong, Y.; Joeng, Y.J.; Jung, G.W.; Shin, W.J; Park, J.W.; Kim, D.H.; Jang, D.K.; Lee, J.H. FET-type gas sensors: A-review. Sens. Actuators B Chem. 2021, 330, 129240. [CrossRef]

8. Jin, H.; Qin, L.; Zhang, L.; Zeng, X.; Yang, R. Review of wide band-gap semiconductors technology. MATEC Web Conf. 2016, 40, 01006. [CrossRef]

9. Vuong, T.A.; Kim, H. Pt-AlGaN/GaN HEMT-based hydrogen gas sensors with without $\mathrm{SiN}_{\mathrm{x}}$ post-passivation. J. IKEE 2019, 23, 1033-1037.

10. ChiChibu, S.F.; Uedono, A.; Kolima, K.; Ikeda, H.; Fujito, K.; Takashima, S.; Edo, M.; Ueno, K.; Ishibashi, S. The origins and properties of intrinsic nonradiative recombination centers in wide bandgap GaN and AlGaN. J. Appl. Phys. 2018, 123, 161413. [CrossRef]

11. Choi, J.H.; Jo, M.G.; Han, S.W.; Kim, H.; Jang, S.; Kim, S.H.; Kim, J.S.; Cha, H.Y. Hydrogen sensors Pd-functionalised AlGaN/GaN heterostructure with high sensitivity and low-power consumption. Electron. Lett. 2017, 53, 1200-1202. [CrossRef]

12. Burk, A.A. Jr.; O'Loughlin, M.J.; Siergiej, R.R.; Agarwal, A.K.; Sriram, S.; Clarke, R.C.; MacMillan, M.R.; Balakrishna, V.; Brandt, C.D. SiC and GaN wide bandgap semiconductor materials and devices. Solid-State Electron. 1999, 43, 1459-1464. [CrossRef]

13. Chen, J.T.; Persson, I.; Nilsson, D.; Hsu, C.W.; Palisaitis, J.; Forsberg, U.; Persson, P.O.Å.; Janzen, E. Room temperature mobility above $2200 \mathrm{~cm}^{2} / \mathrm{V} \cdot \mathrm{s}$ of two-dimensional electron gas in a sharp-interface AlGaN/GaN heterostructure. Appl. Phys. Lett. 2015, 106, 251601. [CrossRef]

14. Chow, T.P.; Tyagi, R. Wide band compound semiconductors for superior high-voltage power devices. In Proceedings of the 5 th International Symposium on Power Semiconductor Devices and ICs, Monterey, CA, USA, 18-20 May 1993; IEEE: Piscataway, NJ, USA, 1993; pp. 84-88.

15. Trivedi, M.; Shenai, K. Performance evaluation of high-power wide band gap semiconductor rectifiers. J. Appl. Phys. 1999, 85, 6889. [CrossRef] 
16. Trivedi, M.; Shenai, K. Practical limits of high-voltage thyristors on wide band-gap materials. J. Appl. Phys. 2000, 88, 7313. [CrossRef]

17. Safarik, D.K.; Schwarz, R.B.; Paglieri, S.N.; Quintana, R.L.; Tuggle, D.G.; Byler, D.D. Composition dependence of the elastic constants of $\beta$-phase and $(\alpha+\beta)$-phase $\mathrm{PdH}_{\mathrm{x}}$. Ultrasonics 2010, 50, 155-160. [CrossRef] [PubMed]

18. Khanuja, M.; Shrestha, S.; Metha, B.R.; Kala, S.; Kruis, F.E. Magnitude and time response of electronic and topographical changes during hydrogen sensing in size selected palladium nanoparticles. J. Appl. Phys. 2011, 110, 014318. [CrossRef]

19. Fisser, M.; Badcock, A.B.; Teal, P.D.; Hunze, A. Optimizing the sensitivity of palladium based hydrogen sensors. Sens. Actuators $B$ Chem. 2018, 259, 10-19. [CrossRef]

20. Choi, J.H.; Kim, H.; Cha, H.Y. Improved Stability of AlGaN/GaN Heterojunction Schottky-diode-type Hydrogen Sensor Using Constant Current Source Operation. J. Semicond. Technol. Sci. 2020, 20, 430-435. [CrossRef]

21. Kim, D.H.; Kim, S.J.; Shin, H.; Koo, W.T.; Jang, J.S.; Kang, J.Y.; Jeong, Y.J.; Kim, I.D. High-Resolution, Fast, and Shape-Conformable Hydorgen Sensor Platform: Polymer Nanofiber Yarn Couple with Nanograined Pd@Pt. ACS Nano 2019, 13, 6071-6082. [CrossRef]

22. Lee, C.T.; Yan, J.T. Sensing mechanism of $\mathrm{Pt} / \beta-\mathrm{Ga}_{2} \mathrm{O}_{3} / \mathrm{GaN}$ hydrogen sensor diodes. Sens. Actuators B Chem. 2010, 147, 723-729. [CrossRef]

23. Lechuga, L.M.; Calle, A.; Golmayo, D.; Briones, F. Hydrogen sensor based on Pt/GaAs Schottky diode. Sens. Actuators B Chem. 1991, 4, 515-518. [CrossRef]

24. Jung, S.; Baik, K.H.; Ren, F.; Pearton, S.J.; Jang, S. Pt-AlGaN/GaN Hydorgen Sensor with Water-Blocking PMMA Layer. IEEE Electron. Device Lett. 2017, 38, 657-660. [CrossRef]

25. Tsukada, K.; Kiwa, T.; Ymaguchi, T.; Migitaka, S.; Goto, Y.; Yokosawa, K. A study of fast response characteristics for hydrogen sensing platinum FET sensor. Sens. Actuators B Chem. 2006, 114, 158-163. [CrossRef]

26. Chen, J.; Zhang, J.; Wang, M.; Li, M. High-temperature hydrogen sensor based on platinum nanoparticle-decorated SiC nanowire device. Sens. Actuators B Chem. 2014, 201, 402-406. [CrossRef]

27. Choo, T.F.; Saidin, N.U.; Kok, K.Y. Hydrogen sensing enhancement of zincoxide nanorode via voltage biasing. R. Soc. Open Sci. 2018, 5, 172372. [CrossRef]

28. Kadhim, I.H.; Hassan, A.H.; Abdullah, Q.N. Hydrogen gas sensor based on nanocrystalline $\mathrm{SnO}_{2}$ thin film grown on bare $\mathrm{Si}$ substrates. Nano-Micro Lett. 2015, 8, 20. [CrossRef]

29. Li, Z.; Yao, Z.; Haidry, A.A.; Plecenik, T.; Xie, L.; Sun, L.; Fatima, Q. Resistive-type hydrogen gas sensor based on TiO 2 : A review. Int. J. Hydrogen Energy 2018, 43, 21114-21132. [CrossRef]

30. Yao, I.C.; Lin, P.; Tseng, T.Y. Hydrogen Gas Sensors Using ZnO-SnO2 Core-Shell Nanostructure. J. Comput. Theor. Nanosci. 2010, 3 , 548-553.

31. Larin, A.; Womble, P.C.; Dobrokhotov, V. Hybrid $\mathrm{SnO}_{2} / \mathrm{TiO}_{2}$ Nanocomposites for Selective Detection of Ultra-Low Hydrogen Sulfide Concentrations in Complex Backgrounds. Sensors 2016, 16, 1373. [CrossRef]

32. Ren, Q.; Cao, Y.Q.; Arulrj, D.; Liu, C.; Wu, D.; Li, W.M.; Li, A.D. Review-Resistive-Type Hydrogen Sensors Based on Zinc Oxide Nanostructures. J. Electrochem. Soc. 2020, 167, 167528. [CrossRef]

33. Chachuli, S.A.M.; Hamidon, M.N.; Mamat, Md.S.; Ertugrul, M.; Abdullah, N.H. A Hydrogen Gas Sensor Based on TiO 2 Nanoparticles on Alumina Substrate. Sensors 2018, 18, 2483. [CrossRef]

34. Choi, P.G.; Izu, N.; Shirahata, N.; Masuda, Y. Fabrication and $\mathrm{H}_{2}$-Sensing Properties of $\mathrm{SnO}_{2}$ Nanosheet Gas Sensors. ACS Omega 2018, 3, 14592-14596. [CrossRef] [PubMed]

35. Xue, N.; Zhang, Q.; Zhang, S.; Zong, P.; Yang, F. Highly Sensitive and Selective Hydrogen Gas Sensor Using the Mesoporous $\mathrm{SnO}_{2}$ Modified Layers. Sensors 2017, 17, 2351. [CrossRef] [PubMed]

36. Zakzewska, K.; Radecka, M. $\mathrm{TiO}_{2}$-Based Nanomaterials for Gas Sensing-Influence of Anatase and Rutile Contributions. Nanoscale Res. Lett. 2017, 12, 1-8.

37. Haviar, S.; Capek, J.; Batkova, S.; Kumar, N.; Dvorak, F.; Duchon, T.; Fialova, M.; Zeman, P. Hydrogen gas sensing properties of $\mathrm{WO}_{3}$ sputter-deposited thin films enhanced by on-top deposited CuO nanoclusters. Int. J. Hydrogen Energy 2018, 43, 22756-22764. [CrossRef]

38. Mirzaei, A.; Kim, J.H.; Kim, H.W.; Kim, S.S. Gasochromic $\mathrm{WO}_{3}$ Nanostructure for the Detection of Hydrogen Gas: An Overview. Appl. Sci. 2019, 9, 1775. [CrossRef]

39. Li, Z.; Yan, S.; Wu, Z.; Li, H.; Wang, J.; Shen, W.; Wang, Z.; Fu, Y. Hydrogen gas sensor based on mesoporous $\mathrm{In}_{2} \mathrm{O}_{3}$ with fast response/recovery and ppb level detection limit. Int. J. Hydrogen Energy 2018, 43, 22746-22755. [CrossRef]

40. Hara, K.; Nishida, N. $\mathrm{H}_{2}$ sensors using $\mathrm{Fe}_{2} \mathrm{O}_{3}$-based thin film. Sens. Actuators B Chem. 1994, 20, 181-186. [CrossRef]

41. Chen, L.; Qi, Z.; Zhang, S.; Su, J.; Somorijai, G.A. Catalytic hydrogen production from methane: A review on recent progress and prospect. Catalyst 2020, 10, 858. [CrossRef]

42. Marchenkov, E.A.; Shipul, V.P. Thermal expansion of semiconductor materials. J. Eng. Thermophys. Rus. 1944, 66, 547-551. [CrossRef]

43. Hashtroudi, H.; Kumar, R.; Savu, R.; Moshkalev, S.; Kawamura, G.; Matsuda, A.; Shafiei, M. Hydrogen gas sensing properties of microwave-assisted 2D Hybrid Pd/rGO: Effect of temperature, humidity and UV illumination. Int. J. Hydrogen Energy 2021, 46, 7653-7665. [CrossRef]

44. Kumar, M.; Kumar, R.; Rajamani, S.; Ranwa, S.; Fanetti, M.; Valant, M.; Kumar, M. Efficient room temperature hydrogen sensor based on UV-activated ZnO-network. Nanotechnology 2017, 28, 365502. [CrossRef] 
45. Kumar, R.; Liu, X.; Zhang, J.; Kumar, M. Room-Temperature Gas Sensors Under Photoactivation: From Metal Oxides to 2D Materials. Nano-Micro Lett. 2020, 12, 164. [CrossRef]

46. $\mathrm{Su}, \mathrm{X} . ;$ Duan, G.; Xu, Z.; Zhou, F.; Cai, W. Structure and thickness-dependent gas sensing response to $\mathrm{NO}_{2}$ under UV irradiation for the multilayered $\mathrm{ZnO}$ micro/nanostructured porous thin films. J. Colloid Interface Sci. 2017, 503, 150-158. [CrossRef] [PubMed]

47. Geng, X.; Luo, Y.; Zheng, B.; Zhang, C. Photon assisted room-temperature hydrogen sensors using PdO load $\mathrm{WO}_{3}$ nanohybrids Int. J. Hydrogen Energy 2017, 42, 6425-6434. [CrossRef]

48. Choi, J.H.; Park, T.H.; Hur, J.H.; Cha, H.Y. AlGaN/GaN Heterojunction Hydrogen Sensor Using ZnO-Nanoparticles/Pd Dual Catalyst Layer. Sens. Actuators B Chem. 2020, 325, 128946. [CrossRef]

49. Sahai, A.; Goswami, N. Probing the dominance of interstitial oxygen defects in $\mathrm{ZnO}$ nanoparticles through structural and optical characterizations. Ceram. Int. 2014, 40, 14569-14578. [CrossRef]

50. Tu, Y.; Chen, S.; Li, X.; Gorbaciova, J.; Gillin, W.; Krause, S.; Briscoe, J. Control of oxygen vacancies in ZnO nanorods by annealing and their influence on ZnO/PEDOT:PSS diode behaviour. J. Mater. Chem. C 2018, 6, 1815-1821. [CrossRef]

51. Khokhra, R.; Bharti, B.; Lee, H.-N.; Kumar, R. Visible and UV photo-detection in ZnO nanostructured films via simple tuning of solution method. Sci. Rep. 2017, 7, 15032. [CrossRef]

52. Choi, J.H.; Anh, V.T.; Kim, H.; Cha, H.Y. High-Sensitivity Hydrogen Sensor Based on AlGaN/GaN Heterojunction Field-Effect Transistor. J. Nanosci. Nanotechnol. 2020, 20, 4404-4408. [CrossRef] [PubMed]

53. Fan, S.-W.; Srivastava, A.K.; Dravid, V.P. UV-activated room-temperature gas sensing mechanism of polycrystalline ZnO. Appl. Phys. Lett. 2009, 95, 142106. [CrossRef]

54. Baik, K.H.; Kim, J.; Jang, S. Highly sensitive nonpolar a-plane GaN based hydrogen diode sensor with textured active area using photo-chemical etching. Sens. Actuators B Chem. 2017, 238, 462-467. [CrossRef]

55. Chung, G.; Cha, H.Y.; Kim, H. Enhanced hydrogen sensitivity of AlGaN/GaN heterojunction gas sensors by GaN-cap layer. Electron. Lett. 2018, 54, 896-897. [CrossRef]

56. Lim, W.; Wright, J.S.; Gila, B.P.; Johnson, J.L.; Ural, A.; Anderson, T.; Ren, F.; Pearton, S.J. Room temperature hydrogen detection using Pd-coated GaN nanowires. Appl. Phys. Lett. 2018, 93, 072109. [CrossRef]

57. Cho, H.J.; Chen, V.T.; Qiao, S.; Koo, W.T.; Penner, R.M. Pt-Functionalized PdO Nanowires for Room Temperature Hydrogen Gas Sensor. ACS Sens. 2018, 3, 2152-2158. [CrossRef]

58. Wang, Z.; Li, Z.; Jiang, T.; Xu, X.; Wang, C. Ultrasensitive Hydrogen Sensor Based on $\mathrm{Pd}^{0}$-Loaded $\mathrm{SnO}_{2}$ Electrospun Nanofibers at Room Temperature. ACS Mater. Interfaces 2013, 5, 2013-2021. [CrossRef] [PubMed]

59. Wang, S.C.; Shaikh, M.O.A. Room Temperature $\mathrm{H}_{2}$ Sensor Fabricated Using High Performance Pt-Loaded $\mathrm{SnO}_{2} \mathrm{Nanoparticles}$ Sensors 2015, 15, 14286-14297. [CrossRef]

60. Wang, H.T.; Kang, B.S.; Ren, F.; Tien, L.C.; Sadik, P.W.; Norton, D.P.; Pearton, S.J.; Lin, J. Hydrogen-selective sensing at room temperature with ZnO nanorods. Appl. Phys. Lett. 2005, 86, 243503. [CrossRef]

61. Cheng, W.; Ju, Y.; Payamyar, P.; Primc, D.; Rao, J.; Willa, C.; Koziej, D.; Niedeberger, M. Large-Area Alignment of Tungsten Oixde Nanowires over Flat and Patterned Substrates for Room-Temperature Gas Sensing. Angew. Chem. Int. Ed. 2015, 54, 340-344. [CrossRef]

62. Simo, A.; Mwakikunga, B.; Sone, B.T.; Julies, B.; Madjoe, R.; Maaza, M. $\mathrm{VO}_{2}$ nanostructures based chemiresistors for low power energy consumption hydrogen sensing. Int. J. Hydrogen Energy 2014, 39, 8147-8157. [CrossRef]

63. Kadhim, I.H.; Hassan, H.A. Room temperature hydrogen gas sensor based on nanocrystalline $\mathrm{SnO}_{2}$ thin fim using sol-gel spin coating technique. J. Mater. Sci. Mater. Electron. 2018, 27, 4356-4362. [CrossRef]

64. Fields, L.L.; Zheng, J.P.; Cheng, Y.; Xiong, P. Room-temperature low-power hydrogen sensor single tin dioxide nanobelt. Appl. Phys. Lett. 2006, 88, 263102. [CrossRef]

65. Xiang, C.; She, Z.; Zou, Y.; Cheng, J.; Chu, H.; Qiu, S.; Zhang, H.; Sun, L.; Xu, F. A room-temperature hydrogen sensor based on Pd nanoparticles doped $\mathrm{TiO}_{2}$ nanotubes. Ceram. Int. 2014, 40, 16343-16348. [CrossRef]

66. Tsai, Y.Y.; Lin, K.W.; Lu, C.T.; Chen, H.I.; Chuang, H.M.; Chen, C.Y.; Cheng, C.C.; Liu, W.C. Investigation of Hydrogen-Sensing Properties of Pd/AlGaAs-Based Schottky Diodes. IEEE Trans. Electron. Devices 2003, 50, 2532-2539. [CrossRef]

67. Liu, I.P.; Chang, C.H.; Ke, B.Y.; Lin, K.W. Study of a GaN Schottky diode based hydrogen sensor with a hydrogen peroxide oxidation approach and platinum catalytic metal. Int. J. Hydrogen Energy 2019, 44, 32351-32361. [CrossRef] 